\title{
Applying External Solutions to Organizational Development: eLearning as a Platform for Internal Growth
}

\author{
Chandana R. Unnithan ${ }^{1}$, Elsie S. K. Chan ${ }^{1}$, Paula M. C. Swatman ${ }^{2}$ \\ 1 School of Information Systems \\ Deakin University \\ Melbourne, Australia \\ chandana@deakin.edu.au \\ elsie@elsiechan.com \\ $2 \quad$ Faculty of Informatics \\ University of Koblenz-Landau \\ Koblenz, Germany \\ paula.swatman@uni-koblenz.de
}

\begin{abstract}
Innovations in technology have facilitated eLearning process development, bringing significant impact into education. eLearning is not simply putting study materials online on the Web, nor is it a substitute for traditional classroom teaching (KPMG, 2002). Businesses worldwide have been using eLearning as a facilitator in organisational development through knowledge sharing, especially in the area of web based training and project management. eLearning has also become a large area of potential business for many organisations. In this study, we explore how eLearning has helped an organisation based in India - Tata Interactive Systems (part of TATA conglomerate), which provides eLearning solutions for businesses locally and globally. In this single case study, we explored how the organisation has not only utilised eLearning as an internal development process, but also successfully converted this learning into business opportunities for itself. To study the development process, we have applied the process theories of Van De Ven and Poole (1995).
\end{abstract}

Keywords: eLearning, case study, organisational change, process theories, teleology, life-cycle theory.

\footnotetext{
The original version of this chapter was revised: The copyright line was incorrect. This has been corrected. The Erratum to this chapter is available at DOI: 10.1007/978-0-387-35617-4_48 


\section{INTRODUCTION}

Technology has enabled the development of eLearning in many ways. During the 1990s, modern technology dramatically increased the possibilities of distance learning - in particular, the WWW not only changed the delivery mode of traditional distance learning, but also revised teaching and learning processes and experiences (Hewett and Goodwin, 1997; Bergner and Bruegge, 1998; Harasim, 1999; Alexander, 2001; Forsyth, 2001; Glasson, 2001; Goff, 2001; Jansen et al., 2002 and Garner, 2002). Networked, online and flexible learning (all of which can be considered eLearning components) have become increasingly popular as a result of the opportunities offered by the Web and offer greater opportunities for learners at a wide variety of levels in society. Although the spectacular bursting of the dot.com bubble meant the demise of many eLearning companies, the corporate world is realising that the Internet can be an extremely powerful tool in on-going employee training, particularly since terrorism and cost cutting has seen business travel dramatically curtailed (Murray, 2001; Simon et al., 2002). Further, IDC believes that more than half of all corporate training is likely to be delivered via technology in the next three to five years (Murray, 2001).

The eLearning industry is growing rapidly. IDC estimates that, by 2005 , over $27 \%$ of business skills training in Europe will be provided via eLearning processes (Nua, 2002). EMarketer reports that $24 \%$ of US organisations are now using eLearning to train their employees (Nua, 2001a). The worldwide corporate eLearning market alone is expected to exceed USD23 billion by 2004 (Nua, $2001 b)$. In the UK, representatives from major groups in education, industry and government have formed a new eLearning taskforce to implement an industryfocused approach to eLearning (Guardian Unlimited, 2002). In the United States, the number of corporate eLearning clients is 9.5-10 million and growing (Washington Post, 2002).

For buyers, acquiring already-existing eLearning products can be less expensive than building the products in-house. For example, Sun Microsystems bought an learning-management system to communicate with its biggest customers (Investor's Business Daily, 2001). Australia's five-university Collaborative Online Learning Information Services consortium joined an existing alliance between US online leaders MIT and Stanford to re-engineer online learning (Richardson, 2002). In India the eLearning market is estimated to grow at 20\% CAGR, and to be worth approx. USD 4 million (IDC 2001). The potential for eLearning applications to be developed in India for use by global corporations has increased during the past 6 years, as India provides a cheaper base for many global corporates to develop their corporate eLearning solutions. 
Despite the enormous potential of eLearning, however, many current eLearning solutions are inadequate due to restricted bandwidth, incompatibility and lack of comparable products within each market (Schutte, 2002; Anderson, 2000). Only a few major organisations (Cisco or KPMG Consulting) truly understand how to get the best out of eLearning, because they have both the necessary infrastructure and a global pool of employees using the technology.

We have looked at an alternative approach to the use of eLearning at the corporate level - using an Indian eLearning organisation which both provides eLearning solutions and applyies them to the organisation's own ongoing educational processes in a learning cycle. The company itself started life as a pilot project within a large Indian conglomerate and has now grown into a sizeable organisation in its own right, with multiple global projects and increasing revenue - using eLearning as a mechanism for learning and growth.

In this paper, we initially discuss the application of eLearning in an organisational context, and introduce our theoretical foundations. We then briefly review the methodology adopted for our case study, before describing the case of Tata Interactive Systems itself, finally drawing conclusions from the learning approach applied by this company to its own development.

\section{UNDERSTANDING ELEARNING}

Elearning is, as we have already pointed out in the introduction to this paper, both fashionable and widely used. But obtaining general agreement on what eLearning comprises can be surprisingly difficult. Peterson et al. (1999) defined the ' $\mathrm{e}$ ' in eLearning from the user's perspective:

exploration: e-learners use the Web as an exploratory tool to access a plethora of information and resources.

experience: the Web offers e-learners a total learning experience, from synchronous learning to threaded discussions to self-paced study.

engagement: the Web captivates learners by enabling creative approaches to learning that foster collaboration and a sense of community.

ease of use: not only is the Web easy to use for learners who are already familiar with the navigation capabilities of the medium, but to learning providers as well, as they can easily make content immediately available to learners across all technical platforms (Windows, N4AC, Unix, etc.).

empowerment: the Web puts learners in the driver's seat with a set of tools that enables personalization of content and allows learners to choose the way in which they best learn. 
Roffe (2002) suggests that the current emphasis of the prefix " $\mathrm{e}$ " in learning applications needs to change from its current meaning of "electronic" to the more supportive descriptions of engagement, enhancement and execution of the learning programme. Attempting to find a consistent and coherent understanding of this potentially confusing term, we identified the following definitions:

eLearning is networked, making it capable of instant updating, storage /retrieval, distribution and sharing of instruction or information. It is delivered to the end-user via a computer using standard Internet technology. It focuses on the broadest view of learning (Rosenberg, 2001:28).

The University of Technology Sydney (2000), which offers degrees in how to develop eLearning educational programmes at the graduate level, highlights the range of activities which can be subsumed under the term eLearning:

e-Learning is learning by means of advanced technologies, such as the internet, intranet, extranet, satellite broadcast, audio/video tape, CDROM and so on. The term e-Learning can be used to describe a range of learning situations, including distance learning, web-based learning, virtual classrooms and more. What they all have in common is the use of communication technologies as a medium for learning.

Brandon-hall.com, a well-known independent research and consulting company in the eLearning sphere, completed a benchmark study in July 2000 of best practices in eLearning across enterprises involving major organisations such as Cisco, Shell, Dell Computers, etc. (Hall and LeCavalier, 2001). The study revealed that the best practice organisations are moving from cost effectiveness to a perception of value. This increased the demand for skills and knowledge delivery over a much shorter cycle delivery time.

Hall argues that organisations are adapting eLearning processes internally to maximize benefits such as access, cost savings and time, while the effort put into developing these processes are justified in terms of performance, accessibility and accountability (Hall and LeCavalier, 2001; Forbes, 2002). Lindhard (2000) suggests that increased time pressure and diminishing technology barriers are enabling the wider application of media-rich eLearning training in organisations. Modular eLearning's attraction is due to its ability to personalise learning experiences. Lindhard states that:

Corporate eLearning is not just 'nice to have' but is a strategic decision to gain competitive advantage through optimal utilisation of the knowledge society's greatest assets - the human capital of well educated and motivated employees (Lindhard, 2000:1-2).

Increasingly, organisations are including eLearning into their internal development and change processes. 


\section{ELEARNING IN AN ORGANISATIONAL ENVIRONMENT}

To study the correlation between organisational change and evolution, we explored Van de Ven and Poole's (1995) organisational development and change theories.

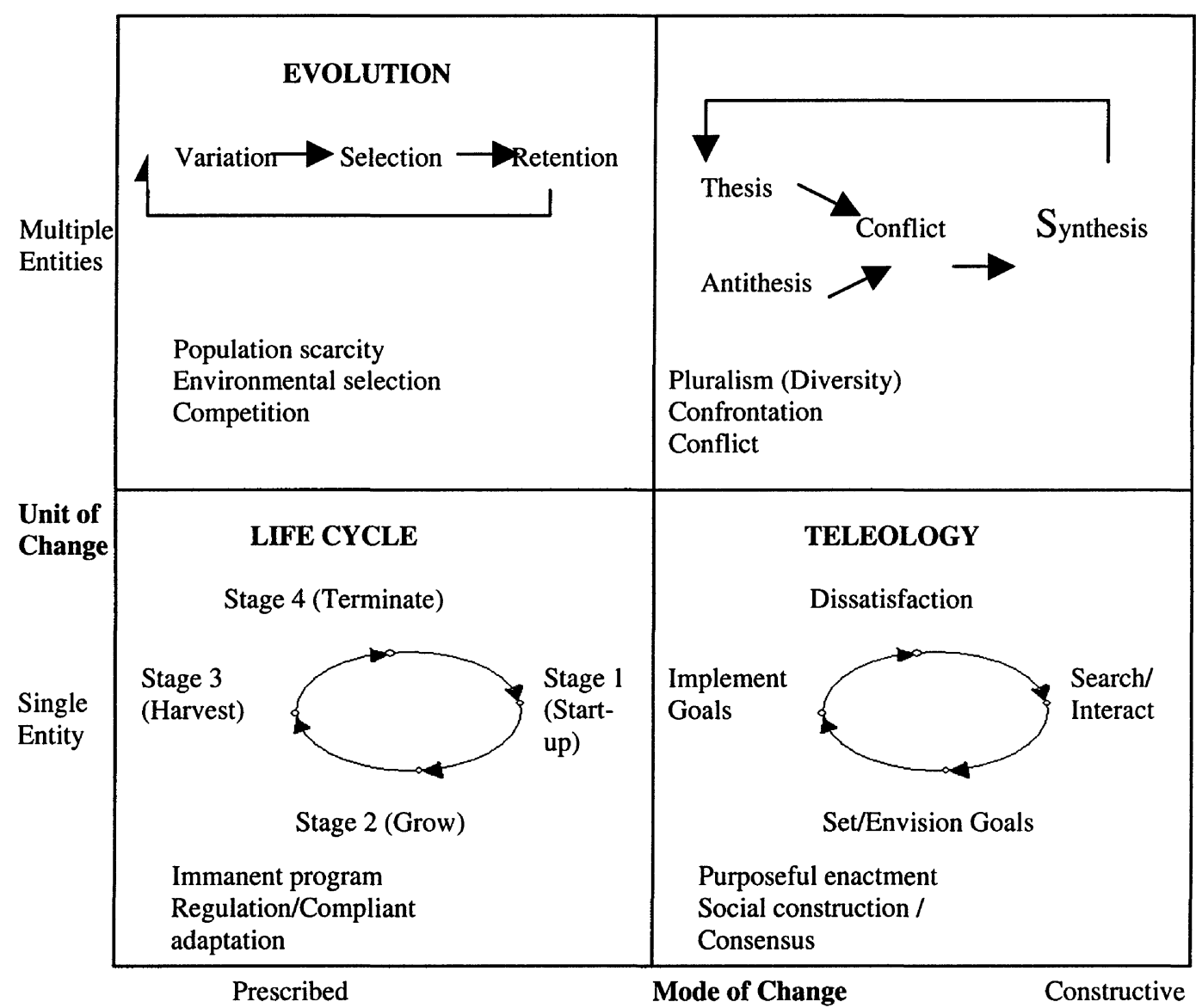

Figure 1: Process theories of organisational development and change (Van de Ven and Poole, 1995: 520).

These authors reviewed 200,000 titles, perused 2000 abstracts and carefully read 200 articles which were useful in identifying 20 different process theories of organisational development or change, which they categorised into 4 process theories - evolutionary, dialectic, life cycle, teleological - as shown in Figure 1. The evolutionary theory is concerned with global changes in organisational 
population (see also Carroll and Hannan, 1989). Singh and Lumsden (1990) apply this approach to explain strategy making within organisations. In the dialectical theory, stability and change are explained by reference to the balance of power between entities. Change occurs when opposing values; forces or events gain sufficient power to confront one another. These two process theories, according to the authors, apply to multiple entities working together. The life cycle theory suggests that change is on-going and that the developing entity contains within itself an underlying form, logic, program or code which regulates the process of change and moves the entity from a given point of departure towards subsequent changes. The teleological theory explains development in organisations by relying on the philosophical doctrine that purpose or goal is the final cause for guiding the movement of an entity. This theory underlies many organisational theories of change, including functionalism (see Merton, 1968), decision making (March and Simon, 1958), epigenesis (Etzioni, 1963), learning (March and Olsen, 1976) and most models of strategic planning and goal setting (Chakravarthy and Lorange, 1991).

We have first applied the life cycle theory to the various phases of eLearning product development within the organisation and the teleological theory, to describe the development process within the organisation itself.

\section{METHODOLOGY}

We had two main focus areas in this investigation. The first was to study the growth of eLearning products within the organisation, and the second, the organisational development itself, through the process of eLearning. There appeared to be two possible research approaches, which would provide the necessary depth and richness - case study and action research - both of which are commonly used in organisational studies.

Rapoport (1970:499) suggests that action research, which requires the subjective involvement of the researcher in the problem under study:

... aims to contribute both to the practical concerns of people in an

immediate problematic situation and to the goals of social science by joint collaboration within a mutually acceptable ethical framework.

Coghlan (2001:51) points out that action researchers are immersed in the organisation and have built up their knowledge from being an actor in the process being studied. Perhaps most importantly from the point of view of this paper, Baskerville and Wood-Harper (1998) identify the importance of the 
"reflective" nature of action research - the aspect which essentially distinguishes action research from consulting:

All action research is reflective in the sense that action is typically followed by a stage in which the researchers reflect on the evaluation of the results and learning from the effects of the action ... What is critical in reflective action research is the actors' discovery of where their behaviour is unexplained by their own understanding (Baskerville and Wood-Harper, 1998:100).

The case study method does not require this reflective, iterative process of hermeneutic exploration, but rather endeavours to investigate a contemporary phenomenon within its real life context (Yin, 1994:13). The level of access and the time required to undertake action research made it unsuitable for our specific needs and we decided in favour of a more traditional, positivist case study approach, basing our understanding of the phenomena under study on Van de Ven and Poole's process theories, particularly their life-cycle and teleological process theories (or purposive action towards a goal).

\section{CASE STUDY}

Tata Interactive Systems (TIS) is a division of the Tata group, India's largest conglomerate, founded over 120 years ago. TIS was established twelve years ago, championed by a visionary picked by the parent company's senior management. Brandon-hall.com's benchmark study of best practices in eLearning states that, in many organisations, a single champion or evangelist is responsible for jump-starting the eLearning implementation (Forbes, 2002).

\section{1 eLearning Product Development - Life Cycle Theory}

Corporations are increasingly implementing web-based training to keep employees up-to-date on new products, services and protocols. Experts believe it to be the fastest growing education industry (Deitel et al., 2001: 490). McKay and Martin (2002) utilize meta-knowledge within the context of web-based learning as a background to the process of scoping eLearning.

The eLearning product concept at TIS predates the WWW. The organisation pioneered the concept of computer based training (CBT) programs in India, through outsourced projects from both overseas and local clients. Initially, the product was based on a simple series of floppy disks. With newer technologies, CD-ROMs became a popular tool for the corporate training process, especially 
in the financial sector. Capitalising on this potential, TIS converted their floppy disk-based CBTs into CD-ROM products, which were further enhanced by multimedia features. The floppy disk-based CBTs were gradually phased out, but the CD-ROMs continued to generate revenue.

With the development of networking technology and the WWW, TIS decided to venture into Web-based training (WBT) programs. Beginning with stage 1 of the life cycle model, the first products were meant for organisations with intranets and extranets, and restricted access. The success and popularity of WBT led to the development of online training programs with many global clients and gradually TIS gained significant expertise in building multimediaenhanced interfaces for the web, and hosting WBT programs from India. Further, the organisation developed its expertise in building virtual simulations for a variety of industry sectors, including universities as well as the corporate banking sector (its original clients).

Following this success, and encouraged by the growth of eCommerce, TIS decided to venture into creating ePortals. With the success of two major ePortals, the company now aims to branch into new areas of eLearning globally, continuing its strategy of steady innovation.

\begin{tabular}{|c|c|l|}
\hline Stage No. & Stage & \multicolumn{1}{c|}{ Example } \\
\hline 1 & Start-up & Computer based training programs \\
\hline 2 & Grow & $\begin{array}{l}\text { Floppy disk to CD-ROM with graphical } \\
\text { enhancements }\end{array}$ \\
\hline 3 & Harvest & CD-ROM products successful \\
\hline 4 & Terminate? & Decided not to terminate \\
\hline \hline 1 & Start-up & Web-based training programs \\
\hline 2 & Grow & Continuous upgrades \\
\hline 3 & Harvest & WBTs successful and popular \\
\hline 4 & Terminate? & Decided not to terminate \\
\hline \hline 1 & Start-up & Eportals \\
\hline \multicolumn{2}{r}{} \\
\hline
\end{tabular}

Table 1: An application of life cycle process theory to TIS

The application of life cycle process theory to eLearning product development at TIS was restricted to the first three stages, except in the case of the first product - floppy disk-based CBT. The other products, although not as significant in volume, continue to yield revenue for the organisation and, therefore, have not been terminated.

\subsection{Organisation Transformation - Teleological theory}


The initial goal of TIS was to integrate technology into learning, and to tap the potential available in the market-place through IT-based learning projects. To provide quality benchmarking, TIS intended from its inception to obtain ISO ${ }^{1}$ and TickIT $^{2}$ certification. From the very beginning, the organisation's goal was to develop a process-based approach to the new business opportunity which eLearning provided, and to use the eLearning tools and principles to evolve the organisation itself over time. Today, TIS has the world's largest team designing and developing customised eLearning solutions - largely, we believe, because the organisation applied teleological theory and set purposive goals from early on in the planning cycle.

TIS began the goal of pioneering CBT in India. The idea took root and was well accepted. As the WWW developed during the early to mid-1990's, and web-based eLearning applications became popular, TIS felt the need to improve its competitiveness. In terms of the teleological cycle, this is the point at which an entity becomes dissatisfied with its own current goals. It was time to reconsider, and set new goals. It was during this time that the CEO (or, as Rosenberg (2001) suggests, the champion or evangelist, who is needed to drive change within an organisation for successful eLearning), envisioned an internal eLearning network which would not only be involved with the experiences of each project, but also with the employees of TIS itself.

According to Rosenberg (2001), once most of the employees in an organisation are interconnected the best way to manage knowledge or disseminate experiences is through an eLearning network, intranet or portal these days most commonly referred to as an Enterprise Network. This Intranet soon became a forum for discussion and sharing of ideas involved in new projects. For example, one of the initial projects was the conversion of videobased materials into web-based training programs, for offer to corporate clients. The development process of this project required participants to be involved in each of the stages, including the design of simple templates which would enable an interactive audio/video-based experience (as compared to the one-way experience of the earlier videos), and the writing of concise content which would enable the ultimate learners to be involved in the interactive learning process. The final output was tested to get the 'actual feel' of how a client would really experience the product, rather than merely testing its technical faults.

These experiences were transferred into the eLearning network, through the vision of the project manager, web content writers, graphic designers, and engineers - each of them offering a unique perspective on the learning process. The learning was converted into a richer picture through each person and experience and, in this evolutionary process, with the sharing of ideas and constant discussions, the original network soon evolved into a version of an 
eLearning portal. The actual project prototypes were circulated within the network, for each of its members to comment on, get the feel of and learn about the process of development that went into the project. One of the most significant trends in learning organisations is the concept of eLearning portals which create a learning community and provide access to content and learning resources (Forbes, 2002) - and this also proved to be the case at TIS.

As teleological theory suggests, searching and interacting with the intention of achieving greater understanding leads to more successful achievement of goals. At TIS, the use of the skills learned through the process of developing eLearning solutions for the furtherance of the organisation's own internal learning, led to the setting of new goals for the company.

The initial goal was the building of more (and increasingly sophisticated) web-based training applications for the rapidly growing corporate eLearning market-place. In the meantime, however, new opportunities for internal growth and development presented themselves. The capability maturity model ${ }^{3}$ (CMM) was fast gaining acceptance among IT companies for its ability to effectively categorise organisations on the basis of their ability to manage data. In this model, TIS saw the means to achieve greater effectiveness in terms of important factors such as $100 \%$ on-time completion of projects, increased productivity, and improved quality assurance for clients. Building on these concepts, TIS became the first company in its category to receive ISO 9001 certification from DNV Britain, and to be assessed at SEI CMM Level 5 (assessment by $\mathrm{KPMG}^{4}$ ). Since obtaining CMM Level 5 certification in 2001, TIS has been able to measure accurately organisational parameters such as productivity, on time project completion, estimation efficiency, dollar realisation and a number of other important benchmarks.

As a result of this teleological process, TIS has become one of the world's largest suppliers of the design and development of customised eLearning solutions. The company has been in business for a decade, with over 500 projects to its credit in the areas of corporate training, education and 'edutainment', learning portals and courseware conversion. To ensure that it fulfils the requirements and expectations of its clients, TIS has focused on creating quality processes and systems guaranteeing reliable, 'on-time' product development. The company's basic product has changed over this period from its initial Computer Based Training CD-ROM applications into Web-based training courseware, with broadband portability. The ePortals, which are now generating business for the organisation, have come out of the brain-storming and idea generation which the internal eLearning enterprise network made possible. Table 2 depicts the iterative teleological process within TIS until 
recently. It can be seen that the constant re-evaluation and development process, as explained through teleological theory continues with this organisation.

\begin{tabular}{|l|l|}
\hline \multicolumn{1}{|c|}{ Iterative Stages } & \multicolumn{1}{c|}{ Example } \\
\hline Setting/Envisioning goals & $\begin{array}{l}\text { Tapping the growing eLearning market through CD } \\
\text { ROM applications, ISO and TICKit certification }\end{array}$ \\
\hline Implementing Goals & $\begin{array}{l}\text { Developing of CD ROM products, obtaining } \\
\text { certifications }\end{array}$ \\
\hline Dissatisfaction & $\begin{array}{l}\text { Increasing competition, web based applications } \\
\text { offering new opportunity }\end{array}$ \\
\hline Search or Interact & Brainstorming through the Intranet \\
\hline \hline Setting/Envisioning goals & $\begin{array}{l}\text { Tapping the web based application market, seeking } \\
\text { CMM levels }\end{array}$ \\
\hline Implementing Goals & $\begin{array}{l}\text { Developing new web based products, CMM } \\
\text { implementation and certification through KPMG }\end{array}$ \\
\hline Dissatisfaction & $\begin{array}{l}\text { Interactive products are expected, ePortal concept } \\
\text { gaining momentum in the world. }\end{array}$ \\
\hline Search or Interact & $\begin{array}{l}\text { Idea generation through the Intranet, converting the } \\
\text { idea of the simple intranet into various vertical } \\
\text { ePortals. }\end{array}$ \\
\hline \hline Setting/Envisioning goals & $\begin{array}{l}\text { Expanding horizons through new eLearning } \\
\text { opportunities globally, the intranet to develop into a } \\
\text { global network, maintain CMM levels. }\end{array}$ \\
\hline & $\ldots$ the process continues ... \\
\hline
\end{tabular}

Table 2: An application of teleological iterative process to TIS

The teleological process of development within TIS set a new standard, not only for other organisations within the Tata conglomerate, but also for other similar or developing organisations within the eLearning domain. Although none of them have so far been flexible enough to completely adapt to this model, and generate further business, many organisations within India have since adopted the idea of the internal eLearning network, to enable smooth facilitation of internal processes and the ongoing growth and evolution which TIS has been able to achieve.

TIS' success has primarily been based on the fact that it has been able to effectively convert its knowledge, built through internal eLearning processes, into successful business opportunities. The constant evaluation and change which the company's eLearning enterprise network has enabled, has helped TIS to evolve into a better performer in a very competitive marketplace. In the process, it has also set an example within the industry generally, and the Indian context specifically, for other organisations - and it has, indeed, created a 
benchmark against which other eLearning solution providers can measure themselves.

\section{CONCLUSION}

In this paper, we have explored the way in which one organisation has been able to apply the concepts and learning techniques developed through its commercial eLearning solutions, developed for external clients, to its own internal development; and how it has converted the learning thus gained into successful new business opportunities. To understand TIS' application of an eLearning enterprise network, we applied Van de Ven and Poole's life cycle and teleological process theories in organisational development to this eLearning organisation, which suggests that the achievement of goals is effected by an organisation's own purposive actions.

eLearning is an impressively fast-moving arena, in which corporations are investing many millions of dollars annually as they search for more effective ways to: train their new recruits; provide on-going education to existing employees as part of their normal career development; and to offer rapid training to in new skills to existing employees under emergency situations (for example, where an employee is taken ill or resigns suddenly). The case study in this paper has shown that eLearning can not only provide external training to companies but, when the principles and skills which underpin eLearning are utilised as a spring-board for internal re-evaluation, it can also be used as an internal hermeneutic tool to enable an organisation to constantly re- invent and re-focus its own goals.

This Indian case study also points to the fact that innovation and the effective use of eLearning is not restricted to the developed world. Revelatory examples of organizational best practices through eLearning may be found in many parts of the world - and offers hope to entrepreneurial organisations who are willing to unlearn and relearn, using innovative eLearning techniques that enable positive transition in the developing world.

\footnotetext{
${ }^{1}$ ISO (International Organization for Standardization), founded in 1947, is a worldwide federation of national standards bodies from some 100 countries, one from each country.

${ }^{2}$ TickIT is a concept of developing quality software and constant improvement based on experience. For detail, refer to http://www.tickit.org/.
} 
${ }^{3}$ The Capability Maturity Model (CMM), published by the Carnegie Mellon Software Engineering Institute (SEI), characterises the software development maturity of organisations based on their practices and procedures. Five levels of the SEI CMM can be mapped to a data perspective based on the manner in which data are stored, managed, and maintained. These 5 levels are: Initial, Repeatable, Defined, Managed and Optimizing. For detail, refer to http://www.sei.cmu.edu/cmm/.

${ }^{4} \mathrm{KPMG}$ is an international company. It was formed in 1987. Innovation centers have been established for each of KPMG's service lines - Assurance, Tax and FAS - which operate as unique multinational research and development "labs." The centers allow KPMG to develop, test, and customize tools and services for specific industries and clients.

\section{REFERENCES}

Alexander, S. E-learning developments and experiences. Education + Training 2001; 43(4/5):240248.

Anderson, C. eLearning in practice-blended solutions in action. IDC Report 2000.

Baskerville, R. and Wood-Harper, T. Diversity in information systems action research methods. European Journal of Information Systems 1998; 7:90-107.

Berger, P. L. and Luckmann, T. The Social Construction of Reality. Garden City, Double Day, New York, 1966.

Bergner, K. and Bruegge, B. Teaching and learning with the Internet. Proceedings of the International Conference Software Engineering: Education \& Practice, 26-29 January, University of Otago, Dunedin, New Zealand, 1998.

Brockbank, B. J. May the E-learning workforce be with you. E Commerce News 2001; 9. $<\mathrm{http}: / / \mathrm{www}$.ecommercetimes.com/perl/story/12344.html> [3rd April 2002].

Carrol, G. and Hannan, M.T. Density Delay in the evolution of organizational populations: a model and five empirical tests. Administrative Science Quarterly, 1989; 34: 411-430.

Chakravarthy, B. S. and Lorange, P. Managing the Strategy Process, Englewood Cliffs, Prentice Hall, US, 1991.

Coghlan, D. Insider Action Research Projects, Implications for Practising Managers. Management Learning 2001; 32(1):49-60.

Deitel, H. M., Deitel, P.J. and Steinbuhler, K. e-Business and e-Commerce for Managers, Prentice Hall, 2001.

Etzioni, A. The epigenesis of political communities at the international level. American Journal of Sociology 1963; 68:407-421.

Forbes eLearning Building Competitive Advantages Through People and Technology 2002. $<h t t p: / / w w w$.forbes.com/specialsections/elearning/e-05.htm> [3 Apr 2002].

Forsyth, I. Teaching and Learning Materials and the Internet, Kogan Page, UK, 2001.

Garner, S. Improving student-tutor dialogues in E-Learning. Proceedings of IS2002 Informing Science + IT Education, 19-21 June, Cork, Ireland 2002:229-234.

Glasson, B. E-Education: two challenges presented in the panel section e-Education: problems, challenges and solutions, the Fourteenth Bled Electronic Commerce Conference, Bled, Slovenia, June 25-26, 2001.

Goff, L. J. E- learning evangelists. Computerworld, Framingham, 10 Sep. 2001. 
Guardian Unlimited E-Learning Taskforce Launched. 31 January 2002.

Hall, B. and LeCavalier, J. E-Learning across the enterprise, the benchmarking study of best practices $2001<$ <ttp://www.grmentor.com/public/web2000/bhc_summary.PDF> [3 Apr 2002].

Harasim, L. A Framework for Online learning: The Virtual-U1. Computer, Sep. 1999:44-49.

Hewett, W. G. and Goodwin, C. The Use of Internet Technology to Enhance the Learning Experience for Students and Provide a Richer Teaching Environment. Proceedings of the 3rd Pacific Asia Conference on Information Systems, Brisbane, Australia, 1-5 April 1997:347-356.

IDC Worldwide Corporate E-learning Market Forecast and Analysis, 1999-2004, IDC \#W23904, April, 2001.

Investor's Business Daily E-Learning Firms Shopping For Bargains, 18 Dec. 2001.

Jansen, W., van den Hooven, H.M., Jägers, H.P.M. and Steenbakkers, G.C.A. The Added Value of E-learning. Proceedings of IS2002 Informing Science + IT Education, 19-21 June, Cork, Ireland 2002:733-746.

KPMG (2002) eLearning- Essential Solutions for the Digital Age, eWorkforce, $<$ Lttp://www.kpmgconsulting.co.uk/research/othermedia/wf9_elearn.pdfs [3 Apr 2002].

Lindhard, G. Corporate eLearning Trends. Technology and Services, 2000:1-2.

March, J. G. and Olsen, J. P. Ambiguity and Choice in Organisations, Universitetsforlaget, Bergen, Norway, 1976.

March, J. G. and Simon, H. A. Organisations, Wiley, New York, 1958.

McKay, E. and Martin, B. The scope of e-Learning expanded horizons for life-long learning. Proceedings of IS2002 Informing Science+IT Education, 19-21 June, Ireland 2002:1017-1029.

Merton, R. Social Theory and Social Structure, Free Press, New York, 1968.

Murray, S. Online training is expected to grow rapidly - driven by content and not technology, Financial Times, December $3^{\text {rd }}, 2001$.

Nua IDC Research: Elearning to pick up in Europe, 2002. $<$ http://www.nua.com/surveys/index.cgi?f=VS\&art_id=905357583\&rel=true> [3 Apr 2002].

Nua eMarketer: Elearning gaining ground in US, November 2001a., $<$ http://www.nua.com/surveys/index.cgi $f=V S \&$ art_id=905357359\&rel=true $>$ [3 Apr 2002].

Nua IDC Research: Corporate eLearning market to skyrocket, March 2nd. 2001b. $<$ http://www.nua.com/surveys/index.cgi $? f=V S \&$ art_id $=905356515 \&$ rel=true $>$ [3 Apr 2002].

Peterson, R. W., Marostica, M. A. and Callahan, L. M. E- learning: Helping Investors Climb the E- learning Curve. U.S. Bancorp Piper Jaffray Equity Research Report, Nov. 1999.

Rapoport, R.N. Three Dilemmas in Action Research. Human Relations 1970; 23(4): 499-513.

Richardson, J. Plug for e- learning Network. Australian IT. 27 Feb 2002.

Roffe, I. E-learning: engagement, enhancement and execution. Quality Assurance in Education 2002; 10(1): 40-50.

Rosenberg, M. J. E-learning, Strategies for Delivering Knowledge in the Digital Age. McGrawHill, USA 2001.

Schutte, S. eLearning - the market is going to grow, Elearning, February $19^{\text {th }} 2002$. $<$ http://www.jobuniverse.com/ne.../index.cfm?fuseaction=Detail_Print\&newsId=101586 \&newArt=education $>$ [3 Apr 2002].

Simon, C., Reckmann, N., Swatman P M C. Initiating elearning via workflow management. University of Koblenz Working Paper, April, 2002.

Singh, J.V and Lumsden C.J. Theory and research in organizational ecology. Annual Review of Sociology 1990; 16:161-195. 
University of Technology Sydney What is e-Learning? UTS: Education 2000. $<$ http://elearning.uts.edu.au/what/index.html> [3 Apr 2002].

Van de Ven, A. H. and Poole, M. S. Explaining development and change in organisations. Academy of Management Review July 1995; 20(3): 510-540.

Washington Post Online education becomes Tech success story for D.C. Area, 12 Feb. 2002.

Yin, R. K. Case Study Research Design and Methods, Sage Publications, 2nd edition 1994.

\section{PERMISSION}

With Permission and Inputs from:

Mr. Sanjay Sharma, CEO, Tata Interactive Systems, India.

Mrs. Punam Medh, DGM - Instructional Design, Tata Interactive Systems, India

Mrs. Candida Chandorkar, Director-Business Development (Australia and New Zealand), Tata Interactive Systems, India. 